\title{
Effects of Light Emitting Diode in Erythrocytes
}

\author{
Hennes Gentil de Araújo', Patricia Froes Meyer'1, Mario Bernardo Filho², \\ Éric Heleno Freire Frederico3, Sebastião David dos Santos Filho1, \\ Marcus Vinicius de Mello Pinto 4 \\ ${ }^{1}$ Universidade Federal do Rio Grande do Norte (UFRN), Natal, Brazil \\ ${ }^{2}$ Universidade Federal do Rio de Janeiro (UFRJ), Rio de Janeiro, Brazil \\ ${ }^{3}$ Universidade Estadual do Rio de Janeiro (UERJ), Rio de Janeiro, Brazil \\ ${ }^{4}$ Instituto Celulare, Centro de Tratamento a Laser e Terapia Celular, Rio de Janeiro, Brazil \\ Email: hennesgentil@yahoo.com.br, orofacial 1@hotmail.com
}

Received 26 June 2014; revised 20 July 2014; accepted 15 August 2014

Copyright (C) 2014 by authors and Scientific Research Publishing Inc.

This work is licensed under the Creative Commons Attribution International License (CC BY).

http://creativecommons.org/licenses/by/4.0/

(c) (i) Open Access

\section{Abstract}

The Light Emitting Diode (LED) is a phototherapy equipment, poorly studied, which is able of acting on blood level and it has frequently appeared in clinical practice of physiotherapy to aid on skin rejuvenation, control inflammation and wound healing. The aim of the study was to evaluate the effects of LED on red blood cells through the spectrophotometer. This is an experimental study with a sample of 5 male Wistar rats weighting between $200 \mathrm{~g}$ and $350 \mathrm{~g}$, randomly selected, anesthetized and $4 \mathrm{ml}$ of blood was collected by cardiac puncture. The blood collected was divided into four groups, one control and three treated, these individually irradiated by blue LED (420 - 490 $\mathrm{nm})$, green LED (515 - $570 \mathrm{~nm})$ and red LED $(620-680 \mathrm{~nm})$ at an output of 3 watts, for 10 minutes and $5 \mathrm{~cm}$ apart from the surface of the blood, then it was analyzed by a spectrophotometer at 540 $\mathrm{nm}$. The results were submitted to Anova and Post-roch Turkey $(p<0.05)$. All wavelengths tested produced hemolysis greater than the control in hypotonic solutions of $\mathrm{NaCl}$ (range 0.02 to $0.06 \mathrm{M})(p$ < 0.01). Only the band between $515-570 \mathrm{~nm}$ provides a higher hemolysis (range 0.06 to 0.1 ) when compared to the control group $(p<0.05)$. The irradiation of blood through the LED therapy was able to weaken the cell membrane of the red blood cells. It is likely that hemolysis does not bring harm the body, because as it is a local therapy, the amount of hemolysis that can be caused is small and it will induce the reproduction of new red blood cells, thus improving their physiological functions.

\section{Keywords}

LED, Blood, Spectrophotometer 


\section{Introduction}

Our body shows influences of physical agents used in the physiotherapy, however little is known about it [1]. The LED is the one which emits light color varying within a wavelength between $390 \mathrm{~nm}$ and $780 \mathrm{~nm}$ [2]. The light emitted by LED is divergent, not coherent and the separation of wavelengths is didactic [3] [4].

The osmotic fragility valuates the ability of the blood cells to remain their membranes stable in the presence of chaotropic agent. That is useful in the health, particularly for Physical Therapists, for the knowledge on effects of LED in the blood due to the increase in clinical practice.

\section{Materials and Methods}

The sample consisted of 5 Wistar rats, Rattus norvegicos albinus, randomly selected weighting between 200 and $350 \mathrm{~g}$. The Wistar rats were chosen for the experiment because they had enough blood without sacrificing many animals to perform the study. All animals were from the vivarium of Instituto de Biologia Roberto Alcântara Gomes da Universidade do Estado do Rio de Janeiro (UERJ) where they received food and water at wil. They were in cages lined with wood shavings; in ambient temperature; light, humidity and stress controlled; manipulated one single time. Moreover, once the animal is manipulated it does not return to the same Vivarium to avoid behavioral influences.

The material used were clinical centrifuge (BIO ENG Ind e Com LTD), spectrophotometer (800 M ANALYSER, Industry Trade Analyser LTDA, São Paulo), sterile and disposable material for handling blood and $5 \mathrm{ml}$ syringe with needle, test tubes, eppendorf, gloves (sterile) and mask. It was necessary to use shelf support for eppendorf, base metal pen holder for the LED, the device manufacturer Biolight Demox electromedical, composed of two cables, each LED individually used $5 \mathrm{~cm}$ away from the surface of the blood as seen in Figure 1.

A blue LED pen with a wavelength of 420 - $490 \mathrm{~nm}$, a green LED with a wavelength of $515-570 \mathrm{~nm}$ and a red LED with a wavelength of 620 - $680 \mathrm{~nm}$ with 03 watts power were applied during ten minutes.

The "fragility curves” were drawn using Microsoft Excel 2010 to study the percentage of lysis or hemolysis (\% hemolysis) in each tube. The data was submitted to the program and BioEstat version 5.0 through Anova and Post-roch Turkey.

The experimental procedures were conducted in accordance with ethical committee for the care and use of animals of Instituto de Biologia Roberto Alcântara Gomes da Universidade do Estado do Rio de Janeiro (UERJ), number protocol CEA/134/2006.

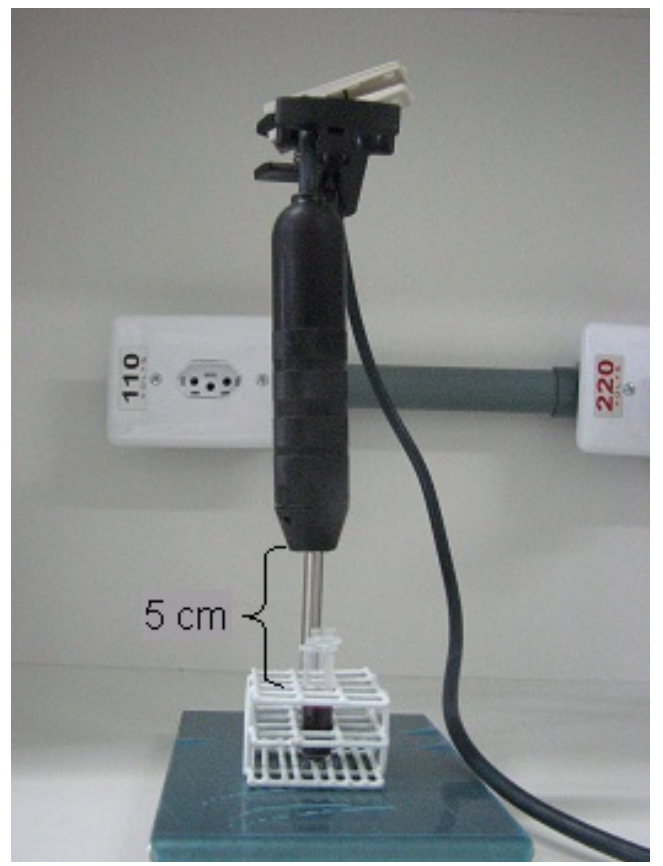

Figure 1. Position of the pen for irradiation of blood. 
Initially a pilot study was conducted. The experiment required four milliliters (ml) of blood from Wistar rat, 1 $\mathrm{ml}$ for each LED pen and $1 \mathrm{ml}$ for the control, withdrawn by cardiac puncture with heparinized syringe. The cardiac puncture was followed by the steps, in the precisely order, below:

- It was deposited $1 \mathrm{ml}$ of blood in a eppendorf by the wall and this sample was irradiated for 10 minutes in a distance of $5 \mathrm{~cm}$ from the surface of blood to the pen tip of the LED;

- The blood was removed with a volumetric pipette 100 microliters $(\mu \mathrm{l})$ of irradiated blood and it was placed in 6 test tubes containing $5 \mathrm{ml}$ clean and dry hypotonic different concentrations of $\mathrm{NaCl}+0.9 \%$ distilled water [5]. The six concentrations contained the following values: Tube $1=0.7 \mathrm{ml} 0.9 \% \mathrm{NaCl}+4.3 \mathrm{ml}$ distilled water, tube $2=1.4 \mathrm{ml} 0.9 \% \mathrm{NaCl}+3.6 \mathrm{ml}$ distilled water, tube $3=2 \mathrm{ml} \mathrm{NaCl} 3 \%+0.9 \mathrm{ml}$ distilled water, tube $4=2.7 \mathrm{ml} 0.9 \% \mathrm{NaCl}+2.3 \mathrm{ml}$ distilled water, tube $5=3.4 \mathrm{ml} 0.9 \% \mathrm{NaCl}+1.6 \mathrm{ml}$ water distilled and tube $6=4 \mathrm{ml} 0.9 \% \mathrm{NaCl}+1 \mathrm{ml}$ distilled water [5].

- The tubes were capped and mixed thoroughly, left to rest at room temperature for 30 minutes and homogenized gently every 15 minutes;

- The samples were centrifuged at $1500 \mathrm{rpm}$ (revolutions per minute) for 5 minutes;

- The supernatants were therefore isolated and removed with a pipette volume of $1000 \mu \mathrm{l}$ and arranged in buckets for analysis;

- It was analyzed the optical density (OD) of hemoglobin for each concentration of $\mathrm{NaCl}$ in a spectrophotometer at $540 \mathrm{~nm}$ (specific value for hemoglobin analysis);

- The optical density of each supernatant with the optical density of the solution with $\mathrm{NaCl}$ [12\%] was compared. The supernatant of this solution is considered white space for preparation, because it has no hemolysis. In trend curve according to the fragility, three intervals were determined: 1 ) the range between $0.12 \%$ and $0.36 \% \mathrm{NaCl} ; 2$ ) the range between $0.36 \%$ and $0.60 \% \mathrm{NaCl}$ and 3) the range between $0.60 \%$ and $0.90 \% \mathrm{NaCl}$ solution [5].

- The animals were sacrificed in $\mathrm{CO}_{2}$ chamber after blood collections.

By confirming the enforceability of the study, there were made 4 new collections that extrictly followed the procedures mentioned above.

\section{Results and Discussion}

Figure 2 shows the curve of hemolysis red blood cells with and without treatment, the expected behavior of erythrocytes when exposed to different concentrations of $\mathrm{NaCl}$. It is divided into three ranges: the first with means hypotonic 0.02 to 0.06 moles, due to the low extracellular concentrations, induces the process of cell turgor and therefore hemolysis is more noticeable [6]. The second interval is presented by the increase in concentrations between hypotonic and isotonic solutions and a third interval revealed isotonic solutions similar to patterns of the human body [5].

It is possible to compare the curved hemolysis of the treated blood with the blue LED visible light (420 - 490 $\mathrm{nm}$ ), and the control. The blue LED is well-known for stimulating the production of proinflammatory cytokines, including interleukin 1 (IL-1), tumor necrosis factor (TNF), and stimulating colony factor of granulocyte and macrophage (GM-CSF). Thus, it appears to be relatively effective especially in the treatment of acne [7].

According to Morris and Davey [9] Hemiglobina or methemoglobin (Hi) has a peak absorption at around 480 $\mathrm{nm}$ initially. When compared to the wavelength of blue LED, specifically methemoglobin is found in greater concentration in the solution which was irradiated by the blue LED when analyzed by the spectrophotometer, justifying a higher level of hemolysis in hypotonic solutions that expressed statistical significance $(p<0.004)$. Some concentrations of carboxyhemoglobin may be found in blood plasma due to radiation of wavelengths between $420-490 \mathrm{~nm}$. The behavior of red blood cells in isotonic concentrations progressed to subsequent assuming the normal pattern superposing the blood without treatment.

One can counteract the behavior of red blood cells treated by the green LED visible light (515 - $570 \mathrm{~nm})$ with untreated blood. The performance of the green LED is essentially the synthesis of fibroblasts, increasing the deposition of type I collagen and reducing the activity of collagenase in dermal papillae [9], which could promote rejuvenating effect. Other studies have also reported that when combined with longer wavelengths the same effects are found [3].

The hemoglobin absorbs more green radiation around $515 \mathrm{~nm}$ second Morris and Davey [8], it is possible to find oxyhemoglobin in the solution when submitted to spectrophotometer. These same authors report that other 


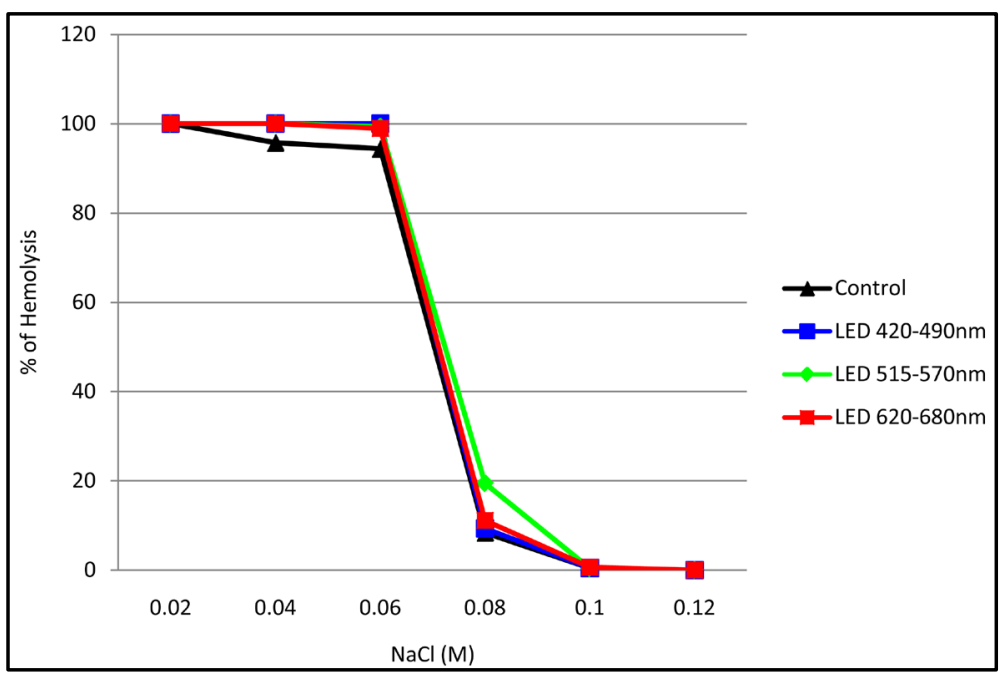

Source: Research data.

Figure 2. The osmotic fragility of red blood cells with and without treatment. Results are expressed as mean \pm standard deviation.

types of hemoglobin as carboxyhemoglobin, deoxyhemoglobin, and methemoglobin also have absorption peaks in the spectrum between 515 - $570 \mathrm{~nm}$, which is observed in the curve of hemolysis when compared to blood control. The values expressed hemolysis greater than the untreated blood what can be justified by various types of hemoglobin, whose absorption peaks are relatively close delimited when in the interval between 515 - $570 \mathrm{~nm}$ spectrum. Such as in the hemolytic disease, the hemolysis stimulates the production of new red blood cells by marrow [10].

The values of hemolysis of the treated blood with the red visible light (620 - $680 \mathrm{~nm}$ ) and the control blood in Figure 2 are explicit. With this wavelength of red LED, it is going to act in the inflammatory process by inhibiting the enzyme cyclooxygenase to prostaglandins, showing the anti-inflammatory action [11].

Besides that, the red LED stimulates the basic energy processes in the mitochondria of each cell sensitising chromophores and cytochrome system, it increases the number of fibroblasts and intracellular mitochondria and controls inflammation, it in progress. It also acts by reducing swelling and stimulating the healing process [12].

With this wavelength the hemoglobin which absorbs more radiation is the Hemiglobina [8]. The absorption peak of this hemoglobin is approximately located at $630 \mathrm{~nm}$ and among the others it is the one that best expresses, justifying its high percentage of hemolysis in hypotonic medium and overlaying the normal behavior in isotonic solutions.

According to Figure 2, it can see in the graph of the trend curve of osmotic fragility of red cell samples treated by the LEDs and the control sample. Only the first interval was statistically significant (Turkey $p<0.01$ and Anova $p<0.0012$ ). Still, the samples treated by the LEDs showed higher percentages of hemolysis, id est the permeabilization of the membrane of the erythrocytes increased in all samples treated by LEDs favoring a higher cell turgor process [6].

The increased presence of hemolysis favored the investigation of specific concentration of hemoglobin that have absorption peaks between 415 - $630 \mathrm{~nm}$. However, there are no reports that the LED 515 - $570 \mathrm{~nm}$, green visible light, may weaken the membrane of red cells. There are a greater number of hemoglobins with a peak absorption within this spectral range, becoming a pathognomonic factor to justify the findings. It has founded a greater number of hemoglobins, as mentioned above, which have their greatest absorption peaks within the spectrum of green light between $515-570 \mathrm{~nm}$.

Although its significance ( $p<0.004$ ANOVA, $p<0.01$ Turkey), it was noted that the lines of bloods treated by the LED as the solutions presented themselves near isotonic blood were overlapping control in the second interval, but notoriously line blood treated by LED 515 - $570 \mathrm{~nm}$ continued indicating a higher percentage of hemolysis (range between 0.06 and 0.1 ).

The purpose of this Figure 3 is to show that the percentage of hemolysis is very low when the LED therapy was apllied in different $\mathrm{NaCl}$ condition, but it does exist. 


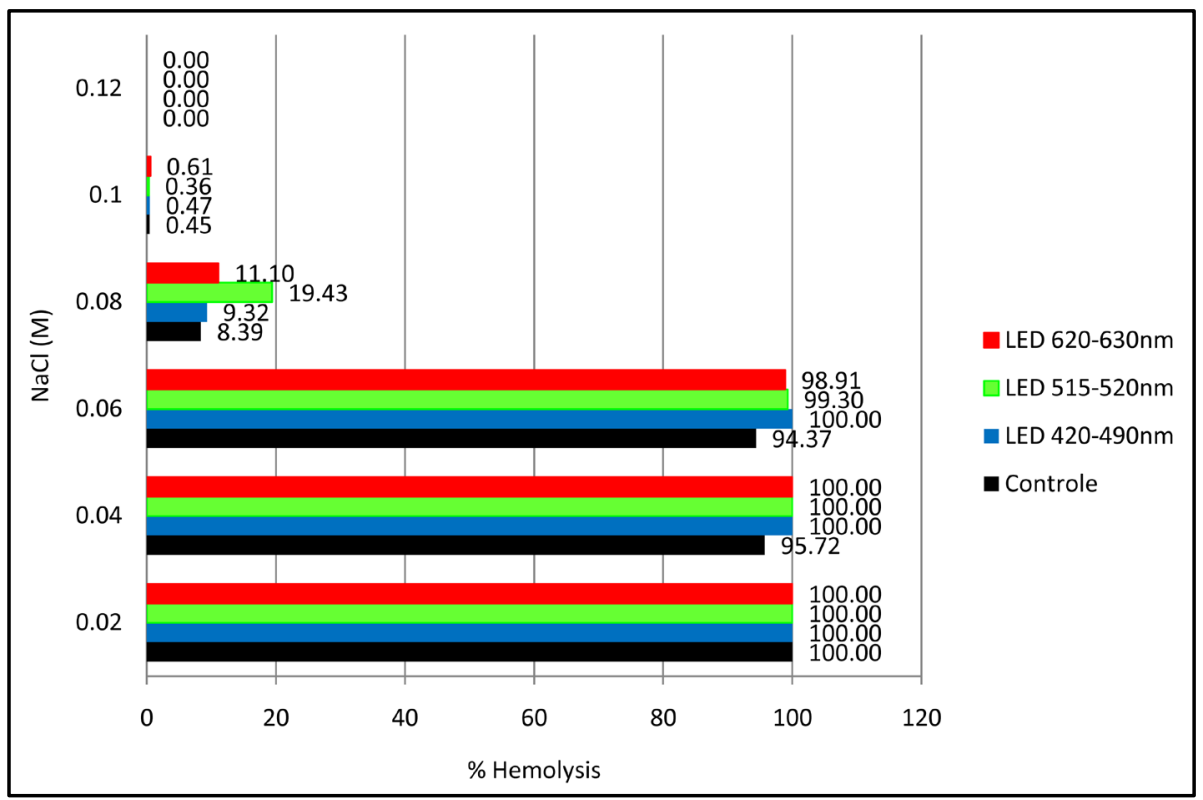

Source: Research data.

Figure 3. The percentage of hemolysis of red blood cells in comparison with the control under each treatment from different $\mathrm{NaCl}$ condition. Results are expressed as mean \pm standard deviation.

It is likely that hemolysis found do not bring harm to the body, because as it is a local therapy, the amount of hemolysis that can be caused is small and it will induce the reproduction of new red blood cells, thus improving their physiological functions

\section{Conclusions}

Irradiation of blood through the LED therapy at wavelengths of 420 - $490 \mathrm{~nm}$ (blue), 515 - $570 \mathrm{~nm}$ (red) and 620 - $680 \mathrm{~nm}$ (red) for 10 minutes was able to weaken the cell membrane of the cells.

All wavelengths tested produced hemolysis greater than the control in hypotonic solutions of $\mathrm{NaCl}$ (range 0.02 to $0.06 \mathrm{M})(p<0.004$ ANOVA, $p<0.01$ Turkey).

Only the range between $515-570 \mathrm{~nm}$ had a higher hemolysis compared to control Anova $(p<0.04)$ and Turkey $(p<0.05)$.

Although there are several Hemoglobins with absorption peaks at different wavelengths, many have an absorbance at around $540 \mathrm{~nm}$ (calibration of the spectrophotometer to measure Hemoglobins), using a close wavelength, in case the green LED can change the red cell structure making it capable of releasing more hemoglobin into the extracellular environment, since most of the absorption peaks of hemoglobin is between 515 - $570 \mathrm{~nm}$. Therefore, there can be greater absorption of liquid from the extracellular medium by red cells or the change in hemoglobin by radiation can make them capable of trespassing the membrane of the weakened erythrocyte.

Even though, more researches involving LEDs and blood cells, altering the doses are recommended.

\section{References}

[1] Meyer, P.F., Filho, S.D.S., Bonelli, L., Fonseca, A.S., Costa, I.C.C., Ronzio, O.A., Neto, J.B., Medeiros, A.C. and Filho, M.B. (2007) Consequences of the Magnetic Field, Sonic and Radiofrequency Waves and Intense Pulsed Light on the Labeling of Blood Constituents with Technetium-99m. Brazilian Archives of Biology and Technology, 50, 117-122.

[2] Moreira, M.C. (2009) Utilização de conversores eletrônicos que alimentam LEDs de alto brilho na aplicação de tecido humano e sua interação terapêutica. Universidade Federal de Santa Maria, Doutorado em Engenharia Elétrica, Santa Maria.

[3] Baez, F. and Reilly, L.R. (2007) The Use of Light-Emitting Diode Therapy in the Treatment of Photoaged Skin. Jour- 
nal of Cosmetic Dermatology, 6, 189-194. http://dx.doi.org/10.1111/j.1473-2165.2007.00329.x

[4] Teider, LD., et al. (2005) Eficiência de dois sistemas de Luz: Halógena x Leds, Publ. UEPG Ci. Biol. Saúde Ponta Grossa, 11, 73-78.

[5] Cavalcanti, T.C., Gregorini, C.C., Guimarães, F., Rettori, O. and Vieira-Matos, A.N. (2003) Changes in Red Blood Cell Osmotic Fragility Induced by Total Plasma and Plasma Fractions Obtained from Rats Bearing Progressive and Regressive Variants of the Walker 256 Tumor. Brazilian Journal of Medical and Biological Research, 36, 887-895. http://dx.doi.org/10.1590/S0100-879X2003000700009

[6] Pimentel, F., Apostolo, H. and Fernandes, R. (2008) IESDE Brasil S.A., Curtiba.

[7] Goldberg, D.J. and Russell, B.A. (2006) Combination Blue (415 nm) and Red (633 nm) LED Phototherapy in the Treatment of Mild to Severe Acne Vulgaris. Journal of Cosmetic and Laser Therapy, 8, 71-75. http://dx.doi.org/10.1080/14764170600735912

[8] Morris, M.W., Davey, F.R. and do Sangue, E.B. (1999) In: Henry, J.B., Ed., Diagnósticos Clínicos e Tratamento por Métodos Laboratoriais, 2nd Edition, Editora Manole Ltda, São Paulo, 411-456.

[9] Weiss, R.A., Macdaniel, D.H., Geronemus, R.G. and Weiss, M.A. (2005) Clinical Trial of a Novel Non-Thermal LED Array for Reversal of Photoaging: Clinical, Histologic, and Surface Profilometric Results. Lasers in Surgery and Medicine, 36, 85-91. http://dx.doi.org/10.1002/lsm.20107

[10] Verrastro, T. (2002) Hematologia e Hemoterapia. Atheneu, São Paulo.

[11] Lim, W., Lee, S., Kim, S., Chung, M., Kim, M., Lim, H., Park, J., Kim, O. and Choir, H.C. (2007) The Anti-Inflammatory Mechanism of $635 \mathrm{~nm}$ Light-Emitting-Diode Irradiation Compared with Existing Cox Inhibitors. Lasers in Surgery and Medicine, 39, 614-621. http://dx.doi.org/10.1002/lsm.20533

[12] Takezaki, S., Omi, T., Sato, S. and Kawana, S. (2006) Light-Emitting Diode Phototherapy at $630+/-3$ nm Increases Local Levels of Skin-Homing t-Cells in Human Subjects. Journal of Nippon Medical School, 73, 75-81. http://dx.doi.org/10.1272/jnms.73.75 
Scientific Research Publishing (SCIRP) is one of the largest Open Access journal publishers. It is currently publishing more than 200 open access, online, peer-reviewed journals covering a wide range of academic disciplines. SCIRP serves the worldwide academic communities and contributes to the progress and application of science with its publication.

Other selected journals from SCIRP are listed as below. Submit your manuscript to us via either submit@scirp.org or Online Submission Portal.
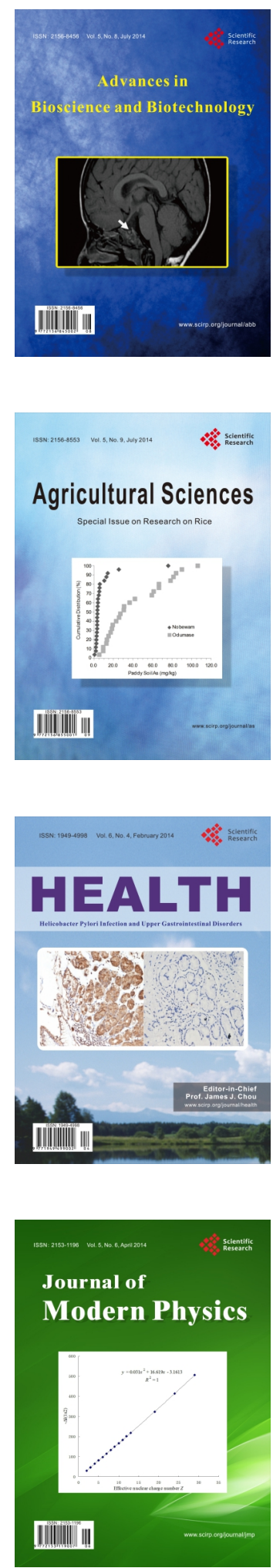
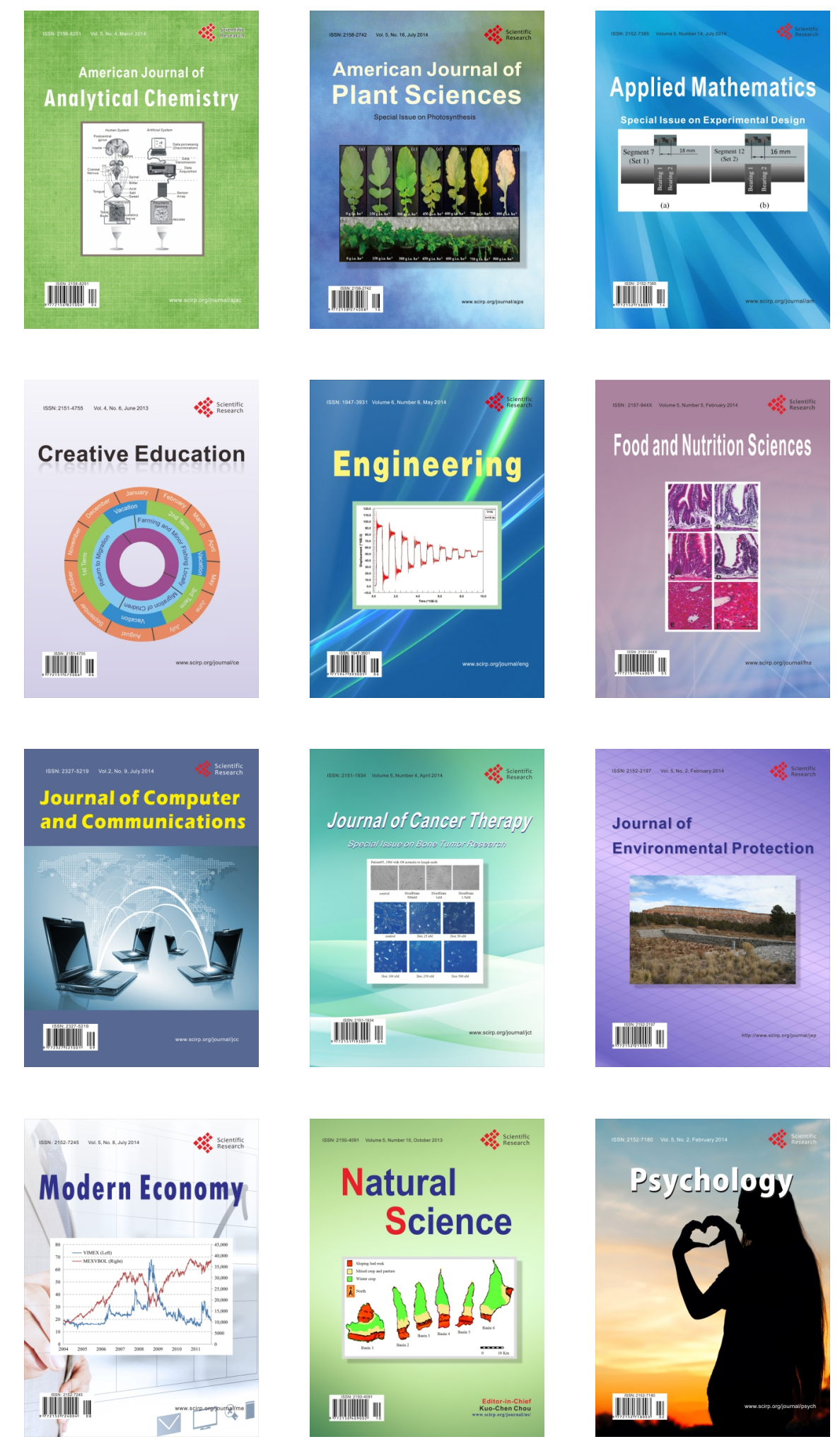